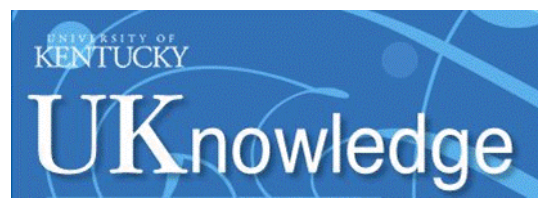

University of Kentucky

UKnowledge

$11-22-2016$

\title{
Individual and Family Protective Factors of Intentional and Unintentional Consumption of Online Pornography in Hong Kong
}

\author{
Cecilia M. S. Ma \\ The Hong Kong Polytechnic University, China \\ Daniel T. L. Shek \\ University of Kentucky \\ Catie C. W. Lai \\ The Hong Kong Polytechnic University, China
}

Follow this and additional works at: https://uknowledge.uky.edu/pediatrics_facpub

Part of the Chinese Studies Commons, Developmental Psychology Commons, and the Family, Life Course, and Society Commons

Right click to open a feedback form in a new tab to let us know how this document benefits you.

\section{Repository Citation}

Ma, Cecilia M. S.; Shek, Daniel T. L.; and Lai, Catie C. W., "Individual and Family Protective Factors of Intentional and Unintentional Consumption of Online Pornography in Hong Kong" (2016). Pediatrics Faculty Publications. 280.

https://uknowledge.uky.edu/pediatrics_facpub/280

This Article is brought to you for free and open access by the Pediatrics at UKnowledge. It has been accepted for inclusion in Pediatrics Faculty Publications by an authorized administrator of UKnowledge. For more information, please contact UKnowledge@lsv.uky.edu. 


\section{Individual and Family Protective Factors of Intentional and Unintentional}

Consumption of Online Pornography in Hong Kong

\section{Digital Object Identifier (DOI)}

https://doi.org/10.1515/ijdhd-2017-7011

\section{Notes/Citation Information}

Published in International Journal on Disability and Human Development, v. 16, issue 4, p. 425-431.

(C2017 Walter de Gruyter GmbH, Berlin/Boston.

The copyright holder has granted the permission for posting the article here. 
Cecilia M.S. Ma*, Daniel T.L. Shek and Catie C.W. Lai

\section{Individual and family protective factors of intentional and unintentional consumption of online pornography in Hong Kong}

DOI 10.1515/ijdhd-2017-7011

Received August 12, 2016; accepted September 10, 2016; previously published online November 22, 2016

\begin{abstract}
The purpose of the current study was to explore how positive youth development and family functioning were related to unintentional and intentional exposure to online pornography in Chinese adolescents. A total of 1401 secondary school students (mean age $=12.43$ ) participated in the study. Findings suggested that positive youth development and family functioning were associated with lower exposure to online pornography. In particular, higher levels of spirituality, social competence, mutuality and communication were associated with lower levels of both types of exposure to online pornography. Discussion focuses on the importance of promoting positive youth development and family functioning as protective factors against the negative influence of pornography among Chinese adolescents.
\end{abstract}

Keywords: Chinese adolescents; family functioning; online pornography; positive youth development.

\section{Introduction}

With the advent of the Internet, the influence of pornography became a significant concern for parents, teachers and policymakers because adolescents often consume pornographic material when surfing the Internet. Prevalence of online pornography consumption varies greatly,

\footnotetext{
*Corresponding author: Cecilia M.S. Ma, Department of Applied Social Sciences, The Hong Kong Polytechnic University, Hunghom, Hong Kong, P.R. China, E-mail: cecilia.ma@polyu.edu.hk Daniel T.L. Shek: Department of Applied Social Sciences, The Hong Kong Polytechnic University, Hong Kong, P.R. China; Centre for Innovative Programmes for Adolescents and Families, The Hong Kong Polytechnic University, Hong Kong, P.R. China; Department of Social Work, East China Normal University, Shanghai, P.R. China; Kiang Wu Nursing College of Macau, Macau, P.R. China; and Division of Adolescent Medicine, Kentucky Children's Hospital, University of Kentucky, Lexington, KY, USA

Catie C.W. Lai: Department of Applied Social Sciences, The Hong Kong Polytechnic University, Hong Kong, P.R. China
}

ranging from $16 \%$ among Chinese adolescents [1] to almost $80 \%$ in German adolescents (93\% of boys and $61 \%$ girls) [2]. Such variation might be due to the failure to distinguish between intentional and unintentional exposure to pornography.

Indeed, the nature of exposure has recently become a central focus in this area of research. For example, about $70 \%$ of adolescents had been unintentionally exposed to online pornography in the USA [3] and Australia [4], while around four-tenths of the adolescents had such experiences in Taiwan [5]. Mesch argued that "as the negative consequences of exposure to pornography depend on the frequency of use, characteristics of adolescents at risk of deliberate exposure to pornography need to be identified and distinguished from those of other youth who use the Internet for more socially acceptable purposes" [6] (p. 602). Unfortunately, although research on the influence of pornography is attracting increasing attention, we know very little about the correlates of these two types of exposure to online pornography. There are different theoretical views on the role of pornography consumption in adolescence. For those adhering to Freudian ideas, they tend to maintain that consumption helps to release tension. However, consuming pornography is also considered a risk factor as adolescents usually engage in other problematic behaviors simultaneously, such as substance abuse [7, 8] and breaking rules [3]. With reference to the latter view, there is a need to understand factors linking intentional and unintentional exposure to online pornography.

Numerous studies indicated the negative outcomes of pornography viewing, such as increased permissive attitudes toward sex $[9,10]$, acceptance of sexual aggression [11] and sexual dissatisfaction [12, 13]. However, few research studies have been conducted to examine the protective factors of adolescent pornography use. There has been a growing body of literature assessing the protective factors, with a recent focus on how individual and family factors may influence exposure to online pornography. In much of the literature it has been found that positive youth development is related to lower odds of adolescent gambling [14], sexual activity/intention, drug abuse [15], intention to engage in 
risky behavior [16] and delinquency [17]. It is posited that developing adolescent competence and strengths would help them minimize the occurrence of behavioral problems and serve to mediate the relationship between life satisfaction and problem outcomes [18]. The positive impacts of positive youth development were well documented in cross-sectional and longitudinal studies. However, not much has been done to assess whether the protective function of this factor varies across two types of exposure to online pornography. The present study attempted to fill this research gap.

Another potentially important protective factor against pornography viewing is family functioning. There is a substantial body of research showing that family functioning is a protective factor for adolescents. Higher family functioning is associated with better psychological well-being [19] and lower likelihood of problematic behaviors, such as substance abuse [20], suicide attempt [21], delinquent behavior [22, 23] and gambling [24]. Recent findings have shown that family functioning reduced the likelihood of pornography viewing among adolescents [25, 26]. This link has been later supported in longitudinal studies when testing the relationship between family functioning at Grade 7 and pornography use at Grade 9 [27] and at Grade 10 [1]. However, little is known whether these associations vary with the nature of exposure. Hence, a better understanding of the conditions of pornography viewing would be useful for identifying protective factors to help educators and practitioners to design policies and programs for protecting adolescents against the negative influence of pornography.

There were two purposes of the present study. First, we explored how positive youth development and family functioning affected adolescents' exposure to online pornography. Second, we compared whether there was any difference between the unintentional and intentional nature of the exposure.

\section{Methods}

Completed questionnaires were collected from 1401 Hong Kong Chinese secondary school students (753 males and 639 females, mean age $=12.43)$. Nine respondents did not indicate their gender. Participants were recruited from 13 schools, located in Hong Kong Island, Kowloon and New Territories. The questionnaire was administered by a trained research assistant and took round 15 min to complete. Ethical approval for the study was obtained from the Hong Kong Polytechnic University institutional review board.

\section{Measures}

Positive youth development was assessed with students' reports on the short form of the Chinese positive youth development scale (CPYDS). The item scale ranged from $1=$ strongly disagree to $6=$ strongly agree. Based on prior measurement invariance results [28], 15 subscales of the CPYDS were explained by four second-order factors, including cognitive-behavioral competencies, prosocial attributes, positive identity and general positive youth development qualities. In the present study, only the general positive youth development qualities with eight first-order factors (bonding resilience, social competence, recognition for positive behavior, emotional competence, moral competence, self-efficacy and spirituality) were used. The scale showed good internal consistency. In Table 1, the internal consistency of this scale was satisfactory (total scale: $\alpha=0.82$, ranging from 0.71 to 0.84 for subscales), except for self-efficacy $(\alpha=0.61)$.

\section{The Chinese family assessment instrument (CFAI)}

Students' perception on their family functioning was assessed using the modified version of CFAI. Students were asked about the three aspects of family functioning, including mutuality (mutual support, love and concern among family members), communication (frequency and nature of interaction among family members) and conflicts and harmony (absence of conflicts and harmonious behavior in the family). This nine-item scale shows good internal consistency and validity [29]. In the present study, the internal consistency of the scale was satisfactory $(\alpha=0.89$; ranging from 0.71 to 0.87 for subscales, see Table 1 ).

\section{Demographic information}

Participants were asked about their age, gender and place of birth.

\section{Data analysis}

Item inter-correlations and Cronbach $\alpha$ coefficients were calculated as a measure of reliability. Associations were examined using Pearson $r$ correlations. Linear regression models were conducted for exploration of the effects of 


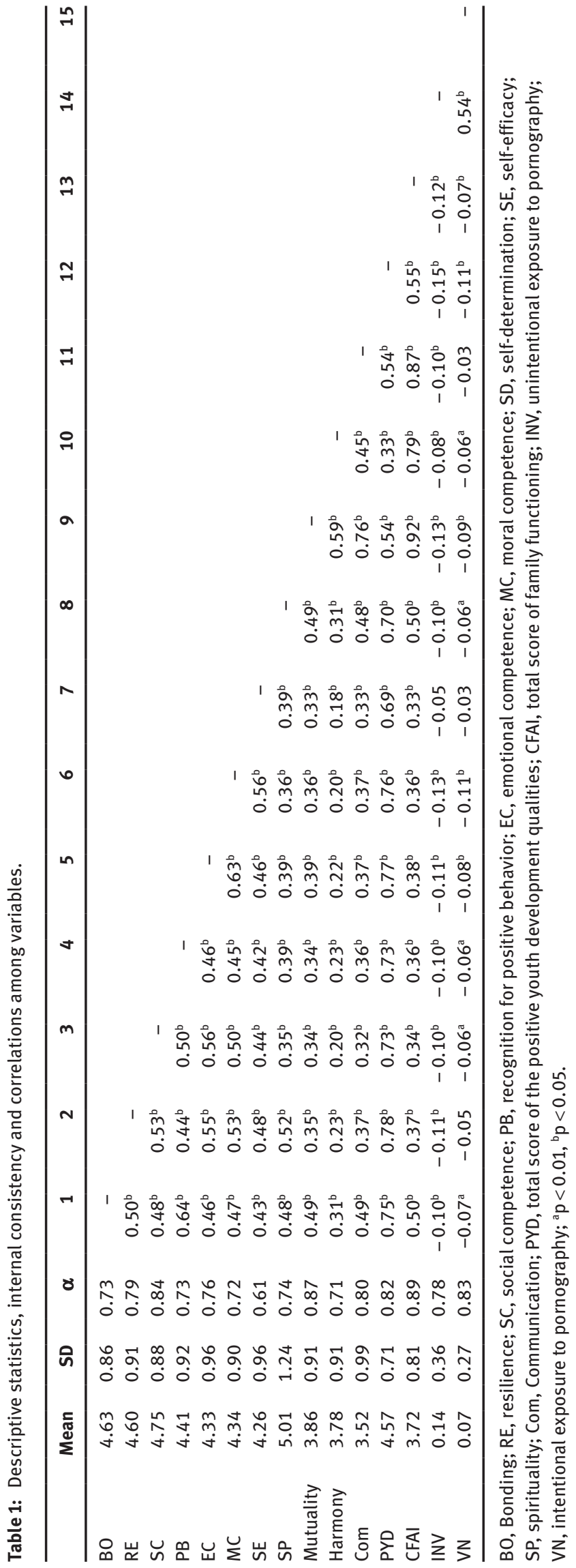

variables. The data were analyzed by using the IBM SPSS Predictive Analytics Software for Windows, version 22, if not specified. Results were considered statistically significant if at or below 0.05 probability level.

\section{Results}

The descriptive statistics and bivariate correlations among the variables are shown in Table 1. All subscales and the overall scores of the CPYDS were significantly correlated $(r=0.39-0.63, \mathrm{p}<0.01)$. All subscales and the overall scores of the CFAI were significantly correlated $(r=0.45-$ $0.59, \mathrm{p}<0.01)$. Analysis based on Pearson correlation showed that all CPYD and CFAI subscales were negatively correlated with the overall intentional and unintentional exposure to pornography $(r=-0.03$ to $-0.13, \mathrm{p}<0.01$ ), except for self-efficacy and resilience. Overall, higher levels of CPYD and CFAI were linked to lower levels of both types of exposure to pornography $(r=-0.07$ to -0.15 , $\mathrm{p}<0.01)$. Intentional exposure to pornography was positively correlated with unintentional exposure to pornography $(r=0.54, \mathrm{p}<0.01)$.

To further examine the impacts of individual and family background characteristics (i.e. CPYDS and CFAI) on both types of exposure to different kinds of pornographic material, multiple regression analyses were used. In these models, intentional and unintentional exposure to different types of pornographic material was regressed on the individual and family factors. The findings based on regression analyses are shown in Tables 2-5.

In Table 2, regarding the predictive effects of positive youth development, spirituality was a significant predictor of intentional exposure to pornographic videos $(\beta=-0.08, \mathrm{p}<0.05)$, unintentional exposure to pornographic stories $(\beta=-0.10, \mathrm{p}<0.01)$ and pictures $(\beta=-0.07$, $\mathrm{p}<0.05)$. Social competence was a significant predictor of both types of exposure to pornographic pictures (unintentional: $\beta=-0.11, \mathrm{p}<0.01$; intentional: $\beta=-0.10, \mathrm{p}<0.01$ ). Resilience was a significant predictor of unintentional exposure to pornographic advertisements $(\beta=-0.09$, $\mathrm{p}<0.05$ ). Results showed that higher levels of exposure were found in individuals with lower levels of spirituality and social and moral competencies.

Among the constructs of family functioning, family mutuality had significant effects on two types of unintentional exposure to pornographic material (videos: $\beta=-0.17, \mathrm{p}<0.01$; websites: $\beta=-0.12, \mathrm{p}<0.01$ ) and four types of intentional pornographic material exposure (videos: $\beta=-0.16, \mathrm{p}<0.01$; chat rooms: $\beta=-0.14, \mathrm{p}<0.01$; 
Table 2: The predictive effects of positive youth development on unintentional exposure to online pornography.

\begin{tabular}{|c|c|c|c|c|c|c|}
\hline \multirow[t]{3}{*}{ Predictor } & \multicolumn{6}{|c|}{ Unintentional } \\
\hline & Stories & Pictures & Videos & Chat rooms & Advertisements & Websites \\
\hline & $\beta^{\mathrm{a}}$ & $\beta^{\mathrm{a}}$ & $\beta^{\mathrm{a}}$ & $\beta^{\mathrm{a}}$ & $\beta^{\mathrm{a}}$ & $\beta^{\mathrm{a}}$ \\
\hline BO & -0.02 & -0.01 & -0.04 & 0.003 & -0.05 & -0.01 \\
\hline $\mathrm{RE}$ & 0.03 & 0.01 & -0.05 & 0.02 & $-0.09^{a}$ & -0.05 \\
\hline $\mathrm{SC}$ & -0.07 & $-0.11^{\mathrm{b}}$ & -0.01 & 0.01 & 0.06 & -0.02 \\
\hline PB & -0.01 & -0.01 & -0.02 & -0.03 & -0.003 & -0.03 \\
\hline $\mathrm{EC}$ & 0.05 & 0.01 & -0.03 & 0.02 & -0.03 & -0.07 \\
\hline MC & -0.07 & -0.02 & -0.02 & -0.03 & $-0.08^{a}$ & -0.02 \\
\hline SP & $-0.10^{b}$ & $-0.07^{a}$ & -0.03 & -0.02 & 0.03 & 0.04 \\
\hline SE & 0.05 & -0.02 & 0.03 & -0.02 & 0.05 & 0.05 \\
\hline $\mathrm{R}$ & 0.14 & 0.17 & 0.13 & 0.06 & 0.14 & 0.11 \\
\hline $\mathrm{R}^{2}$ & 0.02 & 0.03 & 0.02 & 0.00 & 0.02 & 0.01 \\
\hline
\end{tabular}

BO, Bonding; RE, resilience; SC, social competence; PB, recognition for positive behavior; EC, emotional competence; MC, moral competence; SD, self-determination; SP, spirituality; SE, self-efficacy; ${ }^{a} \mathrm{p}<0.05,{ }^{\mathrm{b}} \mathrm{p}<0.01$.

Table 3: The predictive effects of positive youth development on intentional exposure to online pornography.

\begin{tabular}{|c|c|c|c|c|c|c|}
\hline \multirow[t]{3}{*}{ Predictor } & \multicolumn{6}{|c|}{ Intentional } \\
\hline & Stories & Pictures & Videos & Chat rooms & Advertisements & Websites \\
\hline & $\beta^{\mathrm{a}}$ & $\beta^{\mathrm{a}}$ & $\boldsymbol{\beta}^{\mathrm{a}}$ & $\beta^{\mathrm{a}}$ & $\beta^{\mathrm{a}}$ & $\beta^{\mathrm{a}}$ \\
\hline BO & -0.01 & 0.02 & -0.02 & 0.02 & -0.01 & 0.01 \\
\hline RE & 0.03 & -0.01 & -0.01 & -0.001 & -0.02 & -0.02 \\
\hline $\mathrm{SC}$ & -0.02 & $-0.10^{b}$ & -0.01 & -0.02 & 0.03 & 0.02 \\
\hline PB & -0.04 & 0.02 & -0.03 & -0.01 & -0.03 & -0.07 \\
\hline EC & 0.01 & 0.002 & 0.01 & 0.01 & -0.02 & -0.05 \\
\hline MC & -0.06 & -0.06 & -0.05 & 0.03 & 0.003 & -0.02 \\
\hline SP & -0.05 & -0.03 & $-0.08^{a}$ & -0.05 & 0.01 & 0.01 \\
\hline SE & 0.02 & 0.02 & 0.04 & -0.07 & -0.04 & 0.04 \\
\hline $\mathrm{R}$ & 0.09 & 0.13 & 0.12 & 0.08 & 0.06 & 0.09 \\
\hline $\mathrm{R}^{2}$ & 0.01 & 0.02 & 0.02 & 0.01 & 0.004 & 0.01 \\
\hline
\end{tabular}

$\mathrm{BO}$, Bonding; RE, resilience; SC, social competence; $\mathrm{PB}$, recognition for positive behavior; $\mathrm{EC}$, emotional competence; $\mathrm{MC}$, moral competence; SD, self-determination; SP, spirituality; SE, self-efficacy; ${ }^{\mathrm{a}} \mathrm{p}<0.01 ;{ }^{\mathrm{b}} \mathrm{p}<0.05$.

Table 4: The predictive effects of family functioning on unintentional exposure to online pornography.

\begin{tabular}{|c|c|c|c|c|c|c|}
\hline \multirow[t]{3}{*}{ Predictor } & \multicolumn{6}{|c|}{ Unintentional } \\
\hline & Stories & Pictures & Videos & Chat rooms & Advertisements & Websites \\
\hline & $\boldsymbol{\beta}^{\mathrm{a}}$ & $\beta^{\mathrm{a}}$ & $\beta^{\mathrm{a}}$ & $\beta^{\mathrm{a}}$ & $\beta^{\mathrm{a}}$ & $\beta^{\mathrm{a}}$ \\
\hline Mutuality & -0.04 & -0.07 & $-0.17^{c}$ & -0.08 & 0.01 & $-0.12^{c}$ \\
\hline Harmony & -0.003 & -0.03 & -0.03 & $0.08^{b}$ & 0.01 & -0.02 \\
\hline Communication & 0.02 & -0.03 & 0.05 & -0.003 & $-0.08^{b}$ & 0.05 \\
\hline $\mathrm{R}$ & 0.07 & 0.11 & 0.16 & 0.07 & 0.07 & 0.11 \\
\hline $\mathrm{R}^{2}$ & 0.01 & 0.01 & 0.03 & 0.01 & 0.01 & 0.01 \\
\hline
\end{tabular}

${ }^{a}$ Standardized coefficients. ${ }^{b} p<0.01 ;{ }^{c} p<0.05$.

advertisements: $\beta=-0.16, \mathrm{p}<0.01$; websites: $\beta=-0.15$, $\mathrm{p}<0.01$ ). Family communication significantly predicted changes in pornographic advertisements (unintentional: $\beta=-0.08, \mathrm{p}<0.05$; intentional: $\beta=-0.16, \mathrm{p}<0.01)$ and pornographic websites (intentional: $\beta=-0.10, \mathrm{p}<0.05$ ). Results revealed that individuals with higher levels of family mutuality and better communication displayed lower levels of exposure (Tables 4 and 5). 
Table 5: The predictive effects of family functioning on intentional exposure to online pornography.

\begin{tabular}{|c|c|c|c|c|c|c|}
\hline \multirow[t]{3}{*}{ Predictor } & \multicolumn{6}{|r|}{ Intentional } \\
\hline & Stories & Pictures & Videos & Chat rooms & Advertisements & Websites \\
\hline & $\beta^{\mathrm{a}}$ & $\beta^{\mathrm{a}}$ & $\beta^{\mathrm{a}}$ & $\beta^{\mathrm{a}}$ & $\beta^{\mathrm{a}}$ & $\boldsymbol{\beta}^{\mathrm{a}}$ \\
\hline Mutuality & -0.09 & -0.07 & $-0.16^{c}$ & $-0.14^{c}$ & $-0.16^{c}$ & $-0.15^{c}$ \\
\hline Harmony & 0.007 & -0.01 & -0.04 & 0.05 & 0.001 & -0.02 \\
\hline Communication & 0.07 & 0.02 & 0.07 & 0.06 & $0.16^{c}$ & $0.10^{\mathrm{b}}$ \\
\hline $\mathrm{R}$ & 0.06 & 0.06 & 0.14 & 0.08 & 0.11 & 0.11 \\
\hline $\mathrm{R}^{2}$ & 0.003 & 0.004 & 0.02 & 0.01 & 0.01 & 0.01 \\
\hline
\end{tabular}

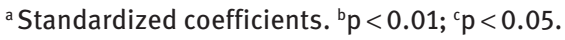

Table 6: The predictive effects of family functioning and positive youth development on two types of exposure to online pornography.

\begin{tabular}{lrrrrrrr}
\hline Predictor & \multicolumn{4}{c}{ Unintentional } & & \multicolumn{2}{r}{ Intentional } \\
\cline { 2 - 4 } \cline { 6 - 8 } & $\mathbf{R}$ & $\mathbf{R}^{2}$ & $\boldsymbol{\beta}^{\mathrm{a}}$ & & $\mathbf{R}$ & $\mathbf{R}^{2}$ & $\boldsymbol{\beta}^{\mathrm{a}}$ \\
\hline PYD & & & $-0.12^{\mathrm{b}}$ & & & $-0.10^{\mathrm{b}}$ \\
CFAI & & & -0.06 & & & -0.03 \\
Model & 0.16 & 0.03 & & 0.11 & 0.01 & \\
\hline
\end{tabular}

PYD, Total score of the positive youth development qualities;

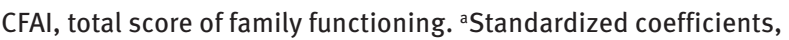
${ }^{\mathrm{b}} \mathrm{p}<0.01$

In general, the overall score of CPYDS was a significant predictor of overall intentional and unintentional exposure to pornography. Positive youth development negatively predicted adolescents' unintentional $(\beta=-0.12$, $\mathrm{p}<0.01)$ and intentional exposure $(\beta=-0.10, \mathrm{p}<0.01)$ to pornography (see Table 6).

\section{Discussion}

The purposes of the study were to explore the individual and family correlates of being exposed to online pornography and to compare the influence of these correlates on pornography exposure. The results of the study were summarized as three major findings.

First, as expected, greater positive youth development was associated with a decrease in both types of exposure to online pornography. Notably, several qualities of positive youth development (e.g. social competence and spirituality) were related to this outcome. People with good social competence usually have better quality social relationships. As previous studies have shown, the good quality of the social relationships was a significant predictor of a smaller likelihood of problematic behavior among adolescents in Slovakia [30], Hong Kong [14, 15] and the USA [6]. Similarly, strong spirituality was related to fewer risky sexual behaviors [31-33]. It seems that students who felt connected were less likely to be intentionally and unintentionally exposed to online pornography. Perhaps, the feeling of being attached to school or others results in a lower engagement in deviant behaviors [34, 35]. The present findings extend the literature on exposure to online pornography.

Second, family functioning was related to a lower level of exposure to online pornography. The family is the primary social environment, which provides closeness and emotional support to the adolescents [36], that shapes adolescents' beliefs and attitudes toward sex. The present study demonstrated that family processes (i.e. mutuality and communication) play an important role in predicting adolescents' exposure to pornography, and thus, is in alignment with previous studies $[8,35,37]$. This finding concurs with previous research that showed that the positive family characteristics of frequent communication among family members and harmony reduced the likelihood of adolescents' problematic behaviors in the Western [38, 39] and Chinese contexts [14, 15].

Third, our analyses showed the protective effects of positive youth development and family functioning on both types of exposure to different types of online pornographic material. Interestingly, positive youth development becomes the only significant predictor when examining the antecedents of both types of exposure to online pornography. This finding may be due to statistical artifact when composite scores of both factors were tested. Future research should adopt a structural equation model method in order to provide a meaningful examination of these antecedents on this behavior [40].

Although the present study is pioneering in its nature, several limitations should be noted. First, the majority of the participants were Hong Kong Chinese adolescents who were sampled from the general adolescent population. 
Therefore, the findings might not be generalizable to other populations. Second, other antecedents, such as peer influence, were not tested in the present study. Peer influence has been found to be a significant predictor of adolescents' problematic behaviors, such as smoking [41] and sexual activity [42]. The inclusion of peer influence might also improve the amount of variance explained when performing the linear regression model analysis. Third, as the current data were based on one measurement time, future study should adopt a longitudinal design to examine the influence of these antecedents across time.

As a whole, with the easy availability and accessibility of the Internet, adolescents are easily exposed to online pornography even if they do not have sexual intent. To protect them against this exposure, prevention efforts aiming at the family alone are not sufficient. Additional focus on the promotion of positive youth development is also necessary. The present study provides support for the influence of individual and family-related antecedents of adolescent's unintentional and intentional exposure to online pornography and sheds light on future youth intervention program.

Acknowledgments: The present study is funded by a grant (Grant no. 25401414) of the Early Career Scheme of the Research Grants Council of the University Grants Committee of Hong Kong.

\section{References}

1. Shek DT, Ma CM. A six-year longitudinal study of consumption of pornographic materials in chinese adolescents in hong kong. J Pediatr Adolesc Gynecol 2016;29:S12-21.

2. Weber M, Quiring O, Daschmann G. Peers, parents and pornography: exploring adolescents' exposure to sexually explicit material and its developmental correlates. Sex Cult 2012;16:408-27.

3. Hasking PA, Scheier LM, Abdallah AB. The three latent classes of adolescent delinquency and the risk factors for membership in each class. Aggress Behav 2011;37:19-35.

4. Flood M. Exposure to pornography among youth in Australia. Aust NZ J Sociol 2007;43:45-60.

5. Chen AS, Leung M, Chen CH, Yang SC. Exposure to internet pornography among taiwanese adolescents. Soc Behav Pers 2013;41:157-64.

6. Mesch GS. Social bonds and internet pornographic exposure among adolescents. J Adolesc 2009;32:601-18.

7. Wolak J, Mitchell K, Finkelhor D. Unwanted and wanted exposure to online pornography in a national sample of youth Internet users. Pediatrics 2007;119:247-57.

8. Ybarra ML, Mitchell KJ. Exposure to internet pornography among children and adolescents: a national survey. Cyberpsychol Behav 2005;8:473-86.
9. Doornwaard SM, van den Eijnden RJ, Overbeek G, ter Bogt TF. Differential developmental profiles of adolescents using sexually explicit internet material. J Sex Res 2015;52:269-81.

10. Lo VH, Wei R. Exposure to internet pornography and taiwanese adolescents' sexual attitudes and behavior. J Broadcast Electron Media 2005;49:221-37.

11. Ybarra ML, Mitchell KJ, Hamburger M, Diener-West M, Leaf PJ. $\mathrm{X}$-rated material and perpetration of sexually aggressive behavior among children and adolescents: is there a link? Aggress Behav 2011;37:1-18.

12. Morgan EM. Associations between young adults' use of sexually explicit materials and their sexual preferences, behaviors, and satisfaction. J Sex Res 2011;48:520-30.

13. Peter J, Valkenburg PM. Adolescents' exposure to sexually explicit internet material and sexual satisfaction: a longitudinal study. Hum Commun Res 2009;35:171-94.

14. Shek DT, Ma CM. Positive youth development and intention to gamble. In: Derevensky J, Shek DT, Merrick J, eds. Adolescent Gambling. Berlin: De Gruyer, 2011.

15. Shek DT, Ma CM. Substance abuse in junior secondary school students in hong kong: prevalence and psychosocial correlates. Int J Child Health Hum Dev 2011;4:433-42.

16. Shek DT. Positive youth development and behavioral intention to gamble among chinese adolescents in hong kong. Int J Adolesc Med Health 2010;22:163-72.

17. Shek DT, Ma CM, Tang CY. Delinquency and problem behavior intention among early adolescents in Hong Kong: profiles and psychosocial correlates. Int I Disabil Hum Dev 2012;11:151-8.

18. Sun RC, Shek DT. Life satisfaction, positive youth development, and problem behaviour among chinese adolescents in hong kong. Soc Indic Res 2010;95:455-74.

19. Shek DT. A longitudinal study of perceived family functioning and adolescent adjustment in chinese adolescents with economic disadvantage. J Fam Issues 2005;26:518-43.

20. Elkington KS, Bauermeister JA, Zimmerman MA. Do parents and peers matter? a prospective socio-ecological examination of substance use and sexual risk among african american youth. J Adolesc 2011;34:1035-47.

21. Wan GW, Leung PW. Factors accounting for youth suicide attempt in hong kong: a model building. J Adolesc 2010;33: 575-82.

22. Barrera M, Biglan A, Ary D, Li F. Replication of a problem behavior model with american indian, hispanic, and caucasian youth. J Early Adolesc 2001;21:133-57.

23. Engels RC, Finkenauer C, van Kooten DC. Lying behavior, family functioning and adjustment in early adolescence. J Youth Adolesc 2006;35:949-58.

24. Casey DM, Williams RJ, Mossière AM, Schopflocher DP, el-Guebaly N, Hodgins DC, et al. The role of family, religiosity, and behavior in adolescent gambling. J Adolesc 2011;34:841-51.

25. Shek DT, Ma CM. Consumption of pornographic materials among hong kong early adolescents: a replication. Scientific World J 2012;2012:8 pages.

26. Shek DT, Ma CM. Consumption of pornographic materials among early adolescents in hong kong: profiles and psychosocial correlates. Int J Disabil Hum Dev 2012;11:143-50.

27. Ma CM, Shek DT. Consumption of pornographic materials in early adolescents in hong kong. J Pediatr Adolesc Gynecol 2013;26:S18-25. 
28. Shek DT, Ma CM. Dimensionality of the Chinese positive youth development scale: confirmatory factor analyses. Soc Indic Res 2010;98:41-59.

29. Shek DT, Ma CM. The chinese family assessment instrument (C-FAl) hierarchical confirmatory factor analyses and factorial invariance. Res Soc Work Pract 2010;20:112-23.

30. Kalina O, Geckova AM, Jarcuska P, Orosova O, Dijk JP, Reijneveld SA. Psychological and behavioural factors associated with sexual risk behaviour among Slovak students. BMC Public Health 2009;9:15-24.

31. Chamratrithirong A, Miller BA, Byrnes HF, Rhucharoenpornpanich O, Cupp PK, Rosati MJ, et al. Spirituality within the family and the prevention of health risk behavior among adolescents in bangkok, thailand. Soc Sci Med 2010;71:1855-63.

32. Love SR. Illicit sexual behavior: a test of self-control theory. Deviant Behav 2006;27:505-36.

33. O'Brien L-A, Denny S, Fleming T, Clark T, Teevale T, Robinson E. The impact of religion and spirituality on the risk behaviours of young people in aotearoa, New Zealand. Youth Stud Aust 2013;32:25-37.

34. Cullen FT, Agnew R, Wilcox P. Criminological theory: past to present. New York: Oxford University Press, 2014.

35. Wight D, Williamson L, Henderson M. Parental influences on young people's sexual behaviour: a longitudinal analysis. J Adolesc 2006;29:473-94.
36. Ainsworth MD. Object relations, dependency, and attachment: a theoretical review of the infant-mother relationship. Child Dev 1969;40:969-1025.

37. Greenfield PM. Inadvertent exposure to pornography on the internet: implications of peer-to-peer file-sharing networks for child development and families. J Appl Dev Psychol 2004;25:741-50.

38. Bersamin M, Todd M, Fisher DA, Hill DL, Grube JW, Walker S. Parenting practices and adolescent sexual behavior: a longitudinal study. J Marriage Fam 2008;70:97-112.

39. Wellings K, Nanchahal K, Macdowall W, McManus S, Erens B, Mercer $\mathrm{CH}$, et al. Sexual behaviour in britain: early heterosexual experience. Lancet 2001;358:1843-50.

40. Hancock GR, Lawrence FR, Nevitt J. Type I error and power of latent mean methods and MANOVA in factorially invariant and noninvariant latent variable systems. Struct Equ Modeling 2000;7:534-56.

41. Poulin C, Graham L. The association between substance use, unplanned sexual intercourse and other sexual behaviours among adolescent students. Addiction 2001;96:607-21.

42. Miller BC, Norton MC, Curtis T, Hill EJ, Schvaneveldt P, Young $\mathrm{MH}$. The timing of sexual intercourse among adolescents family, peer, and other antecedents. Youth Soc 1997;29:54-83. 